\title{
Improved DBP elimination from swimming pool water by continuous combined UV and ozone treatment
}

\author{
Cheema, Waqas Akram; Andersen, Henrik Rasmus; Speht Kaarsholm, Kamilla Marie
}

Published in:

Water Research

Link to article, DOI:

10.1016/j.watres.2018.09.030

Publication date:

2018

Document Version

Peer reviewed version

Link back to DTU Orbit

Citation (APA):

Cheema, W. A., Andersen, H. R., \& Speht Kaarsholm, K. M. (2018). Improved DBP elimination from swimming pool water by continuous combined UV and ozone treatment. Water Research, 147, 214-222.

https://doi.org/10.1016/j.watres.2018.09.030

\section{General rights}

Copyright and moral rights for the publications made accessible in the public portal are retained by the authors and/or other copyright owners and it is a condition of accessing publications that users recognise and abide by the legal requirements associated with these rights.

- Users may download and print one copy of any publication from the public portal for the purpose of private study or research.

- You may not further distribute the material or use it for any profit-making activity or commercial gain

- You may freely distribute the URL identifying the publication in the public portal 


\section{Accepted Manuscript}

Improved DBP elimination from swimming pool water by continuous combined UV and ozone treatment

Waqas.A. Cheema, Henrik.R. Andersen, Kamilla.M.S. Kaarsholm

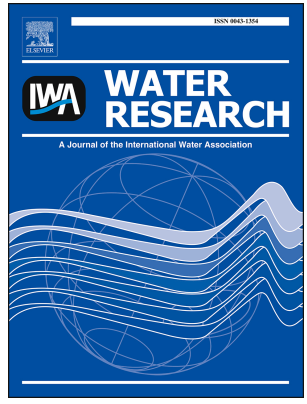

PII:

S0043-1354(18)30745-0

DOI:

10.1016/j.watres.2018.09.030

Reference: WR 14080

To appear in: Water Research

Received Date: 18 May 2018

Revised Date: 20 August 2018

Accepted Date: 17 September 2018

Please cite this article as: Cheema, W.A., Andersen, H.R., Kaarsholm, K.M.S., Improved DBP elimination from swimming pool water by continuous combined UV and ozone treatment, Water Research (2018), doi: https://doi.org/10.1016/j.watres.2018.09.030.

This is a PDF file of an unedited manuscript that has been accepted for publication. As a service to our customers we are providing this early version of the manuscript. The manuscript will undergo copyediting, typesetting, and review of the resulting proof before it is published in its final form. Please note that during the production process errors may be discovered which could affect the content, and all legal disclaimers that apply to the journal pertain. 


\section{Graphical Abstract}
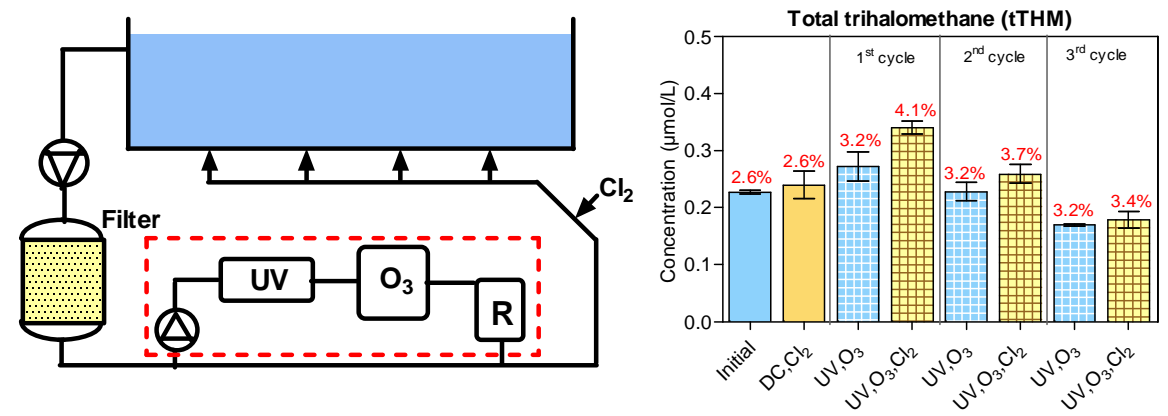
1 Improved DBP elimination from swimming pool water by

2 continuous combined UV and ozone treatment

3 Waqas A. Cheema ${ }^{1,2}$, Henrik R. Andersen ${ }^{2 *}$, Kamilla M. S. Kaarsholm ${ }^{2}$

$4 \quad{ }^{1}$ National University of Sciences \& Technology, H-12 Islamabad, 44000, Pakistan

$5 \quad{ }^{2}$ Department of Environmental Engineering, Technical University of Denmark, 2800 Lyngby, Denmark

$6 \quad *$ Corresponding author: Henrik@ ndersen.net

\section{Abstract}

8 Chlorine is the most frequently used disinfectant and oxidant for maintaining swimming pool water quality;

9 however, it reacts continuously with dissolved organic matter to produce disinfection by-products (DBPs), which are a health risk for pool users. UV treatment is used widely to remove chloramines, which are the most prevalent group of DBPs, albeit chloro-organic DBP concentrations often increase during post-UV chlorination.

In this work, UV and ozone treatments were investigated as additional technologies to eliminate DBP formation and their precursors. Batch experiments were conducted under controlled conditions, using realistic UV and ozone dosages and real pool water samples collected from a public swimming pool.

A gradual increase in all investigated DBP concentrations and predicted toxicity was observed during chlorination after repeated UV treatments, and concentrations of certain DBPs also increased during postozone chlorination. Based on ozone and chlorine's similar reactivity, ozone was used directly after UV treatment to decrease the induction of DBP formation. Most DBP concentrations decreased during repeated combined treatments. It was also observed that DBP formed by post-ozone chlorination was removed by

21 photolysis, thereby indicating synergy between the treatments. Repeated treatments using realistic UV and ozone dosages predicted that water quality will improve as a result of continuous combined UV and ozone treatments. 


\section{Introduction}

Chlorine is used in swimming pools as a disinfectant to minimise the risk of exposure to microbial pathogens. However, one important drawback of swimming pool chlorination is the formation of potentially harmful disinfection by-products (DBPs) ${ }^{1}$, including trihalomethanes (THMs), haloacetonitriles (HANs), chloramines and chloral hydrates, formed mostly through reactions between free chlorine and organic matter from swimmers (Chowdhury et al., 2014; Kristensen et al., 2009; WHO, 2006). Some DBPs are genotoxic and thus might be carcinogenic (Richardson et al., 2007), so they should be minimised through different treatment methods targeting either precursors or by-products.

In recent years, UV treatment has been used extensively in swimming pools, as it has been proven to be efficient in photodecaying chloramines (PWTAG, 2009; Soltermann et al., 2014); however, it has been found that it accelerates the formation of choro-organic by-products, e.g. dichloroacetonitrile, and also promotes free chlorine consumption (Cheema et al., 2017; Cimetiere and De Laat, 2014; Spiliotopoulou et al., 2015). UV treatment of swimming pool water appears to break relative non-reactive organic molecules into smaller molecules, which then react quickly with chlorine (Spiliotopoulou et al., 2015). It has been observed that bromine-containing DBPs generally photolyse faster with UV treatment than DBPs that only contain chlorine (Hansen et al., 2013b). In experiments with UV treatment followed by chlorination, simulating UVtreated pool water returned to a continuously chlorinated swimming pool, the formed DBPs in the chlorination tend to contain more bromine than the DBP found in the original pool sample (Spiliotopoulou et al., 2015). This can be explained by the fact that swimming pools, generally, do not contain inorganic bromide in the pool water, since the bromide that might enter the pool is oxidised to hypobromous acid, which forms bromorganic DBPs faster than chlorine forms DBPs. As a result of the general photosensitivity of organic bromine, bromide is formed during UV treatment from any bromine-containing organic matter and is oxidised by chlorine to form mainly volatile DBPs (Spiliotopoulou et al., 2015).

\footnotetext{
${ }^{1}$ DBP, disinfection by-product; DPD, N,N-diethyl-p-phenylenediamine; DOC, dissolved organic carbon; HAA, haloacetic acid; HAN, haloacetonitrile, LOD, limit of detection; LOQ, limit of quantification; tHAN, total haloacetonitrile; THM, trihalomethan; tTHM, total trihalomethan; UV,
} 
Ozonation has also been used in swimming pools to decrease disinfection by-products, but it is difficult to utilise, as it cannot be allowed in the pool due to toxicity to swimmers. Furthermore, it has been found that most common DBPs react slowly with ozone (Eichelsdörfer and Jandik, 1985). Moreover, ozone reacts well with freshly added organic matter but slowly with organic matter remaining after extended chlorination (Hansen et al., 2016). A recent study also reported that a reaction with fresh organic matter decreases the formation of chlorination by-products, while a slow reaction with already chlorinated organic matter produces organic matter that produces more by-products as a result of chlorination (Hansen et al., 2016).

A combined UV followed by ozonation treatment could increase the reactivity of organic matter to ozone, and ozonation can remove by-products in the swimming pools (Cheema et al., 2017). Cheema et al. (2017) reported a decrease in DBP concentration with the combined treatment followed by chlorination in swimming pool water. However, unrealistically high doses of UV and ozone were investigated during the study (Cheema et al., 2017). Therefore, understanding the use of realistic doses of UV and ozone for a combined treatment system, to see the effect of continued treatment, could help in designing a more efficient treatment system to minimise DBPs in swimming pools. Thus, experiments were performed for the present study in cycles with realistic doses of UV and ozone, in order to investigate the effect of continued treatment.

\section{Material and methods}

\subsection{Reagents and standard analysis}

All chemicals and reagents were purchased from Sigma-Aldrich, Denmark. The experimental set-up for ozonation was based on a $20 \mathrm{~g} / \mathrm{h}$ ozone generator from $\mathrm{O}_{3}$-Technology $\mathrm{AB}$ (Vellinge, Sweden), which was supplied with dry oxygen gas. Generated ozone was dispersed through a diffuser in a collection bottle containing ultra-pure water, which was immersed in an ice bath so that ozone solubility would be maximised. To increase further the solubility of ozone, a manometer and valve were placed after the collection bottle, and a pressure of 1.4 barG was applied. Based on these experimental conditions, the concentration of ozone achieved in the stock solution was between 80 and $100 \mathrm{mg} / \mathrm{L}$. 
Ozone was quantified via a colorimetric method using indigotrisulfonate (Bader and Hoigné, 1981). Reagents used were $0.5 \mathrm{M}$ phosphate buffer at $\mathrm{pH} 2$ and $1.00 \mathrm{~g} / \mathrm{L}$ potassium indigotrisulfonate dissolved in $20 \mathrm{mM}$ phosphoric acid, a further description for which can be found in Hansen et al. (2016). Free and total chlorine in the collected pool water samples was measured using the colorimetric method based on the oxidation of diethyl-p-phenylenediamine (DPD), with and without the addition of iodide, while residual chlorine during the experiment was determined by employing the colorimetric method, using 2, 2-azino-bis (3-ethylbenzothiazoline)-6-sulfonic acid-diammoniumsalt (ABTS), as described by Pinkernell et al. (2000). Non-volatile organic carbon in the pool water samples was quantified with a Shimadzu ASI-V UVC/Persulphate analyser with a sample injection volume of $3 \mathrm{~mL}$. A calibration curve was formed by using potassium hydrogen phthalate standards, with concentrations ranging from 50 to $2000 \mu \mathrm{g} / \mathrm{L}\left(\mathrm{R}^{2}=0.9994\right)$. The method quantification limit was $50 \mu \mathrm{g} / \mathrm{L}$. Non-volatile organic carbon is referred to herein as 'dissolved organic carbon' (DOC).

\subsection{Water sampling}

Pool water samples were collected from a public swimming pool and used for experiments on the day of collection. The pool for water collection was the main practice pool at Gladsaxe (Denmark) - a typical public pool (temperature $26^{\circ} \mathrm{C}$, sand filter with flocculation and a side stream-activated carbon filter) with a hydraulic retention time (HRT) of 4 hours. Water for filling the pool is obtained from the public distribution network, which comprises non-chlorinated groundwater.

\subsection{Disinfection by-products}

Samples were analysed by purge and trap (purge temperature $=30^{\circ} \mathrm{C}$, Velocity XPT Purge and Trap Sample Concentrator, Teledyne Tekmar, with auto-sampler: AQUATek 70, Teledyne Tekmar) coupled with a GCMS (HP 6890 Series GC System, 5973 Mass selective detector, Hewlett Packard), and the analyses were conducted as described by Hansen et al. (2012a).

The employed method detects the following compounds: chloroform, bromodichloromethane, dibromochloromethane, bromoform, dichloroacetonitrile, bromochloroacetonitrile, dibromoacetonitrile, 
trichloroacetonitrile, trichloropropanone, dichloropropanone and trichloronitromethane. The limit of detection (LOD) and limit of quantification (LOQ) were expressed as LOD $=\mathrm{X}_{\mathrm{b} 1}+3 \mathrm{~S}_{\mathrm{b} 1}$ and $\mathrm{LOQ}=\mathrm{X}_{\mathrm{b} 1}+$ $10 \mathrm{~S}_{\mathrm{b} 1}$, where ' $\mathrm{X}_{\mathrm{b} 1}$ ' is the mean concentration of the blank and $\mathrm{S}_{\mathrm{b} 1}$ is the standard deviation of the blank. The LOQ values for all compounds were: chloroform $(0.6 \mu \mathrm{g} / \mathrm{L})$, bromodichloromethane $(0.6 \mu \mathrm{g} / \mathrm{L})$, dibromochloromethane $(0.2 \mu \mathrm{g} / \mathrm{L})$, dichloroacetonitrile $(0.6 \mu \mathrm{g} / \mathrm{L})$, bromochloroacetonitrile $(0.4 \mu \mathrm{g} / \mathrm{L})$, trichloropropanone $(1.0 \mu \mathrm{g} / \mathrm{L})$, dichloropropanone $(1.0 \mu \mathrm{g} / \mathrm{L})$ and trichloronitromethane $(0.6 \mu \mathrm{g} / \mathrm{L})$.

\subsection{Treatments}

\subsubsection{UV treatment}

Treatment was conducted using a quasi-collimated beam apparatus with a doped, medium pressure lamp $(\mathrm{P}=$ $700 \mathrm{~W}$, ScanResearch, Denmark). To ensure constant spectra and emission output, the lamp was turned on half an hour before the experiment. Petri dishes $(350 \mathrm{~mL})$ were used as reaction vessels, while samples were maintained headspace-free and covered by a disc of quartz glass, to limit the volatilisation of the treated sample. To ensure homogeneity during irradiation, samples were mixed gently with a stirrer. The UV dose was determined according to a method described by Hansen et al. (2013b). In summary, UV exposure in the collimated beam set-up was correlated with a real flow-through system on a pool, using the removal of combined chlorine. A UV system needs $1.0 \mathrm{kWh} / \mathrm{m}^{3}$ to remove $90 \%$ of the combined chlorine, and so for the collimated beam set-up, the required radiation time to remove this $90 \%$ from the pool water was 12.3 mins. In order to compare the experimental UV dose to a realistic treatment level, the UV system in the Gladsaxe swimming pool's hot water basin was used. This system consists of 4 UV lamps using a total of $2800 \mathrm{~W}$ and operating 24 hours per day on a total pool volume of $50 \mathrm{~m}^{3}$ (Kristensen et al., 2010, 2009). Therefore, the applied electrical energy dose from UV was $1.34 \mathrm{kWh} /\left(\mathrm{m}^{3} \cdot \mathrm{d}\right)$, and so it can be calculated that the dose equivalent to one day of treatment was achieved after 19 minutes of radiation. To test the stability of the UV system, the removal efficiency of monochloramine was determined in the collimated beam set-up for each experiment. 


\subsubsection{Ozone treatment}

Ozonation was achieved by adding an amount of ozone stock solution to a water sample, which resulted in a maximum $10 \%$ dilution of the sample, and the concentrations were back-calculated according to actual dilution. Ozone dosage was determined by adding a sufficient amount of potassium indigotrisulfonate and a phosphate buffer to a separate ultra-pure water sample and then measuring the absorbance of the unreacted indigotrisulfonate. A detailed description can be found in Hansen et al. (2016).

\subsubsection{Chlorination assay}

The formation of DBPs as a result of chlorination was investigated using a standardised DBP formation assay. Similar tests have been used in other studies investigating the potential for the formation of $\mathrm{NCl}_{3}$ (Schmalz et al., 2011), THM and haloacetic acid (HAA) in swimming pool water (Kanan, 2010), THM, HAN and HAA from synthetic body fluid (Hansen et al., 2012a) and particles from pools (Hansen et al., 2012b). The effect of chlorine concentration in the assay was also recently investigated by Hansen et al. (2013a), and in the current study, the same approach was used to simulate chlorination in the pool after the return of UV/ozone-treated water. Residual chlorine was adjusted to $1 \pm 0.3 \mathrm{mg} \mathrm{Cl} / \mathrm{L}$ after 24 hours at $25^{\circ} \mathrm{C}$ (measured by ABTS). Samples for the DBP analyses were dosed with ammonium chloride solution (50 $\mathrm{mg} / \mathrm{L}$ ), to quench free chlorine, which neither affects the already formed DBP (Kristiana et al., 2014) nor increases N-DBP formation (Hua et al., 2014).

\subsection{Treatment experiments}

\subsubsection{UV treatment experiment}

Samples from the pool water were UV-irradiated and then chlorinated for 24 hours according to section 2.4.3. After $24 \mathrm{~h}$, samples were again UV-irradiated, for the purpose of repeating the treatment in cycles, and subsequently chlorinated. Furthermore, a similar procedure was adopted for repeating treatments in the third cycle. 
146 Pool water samples were ozonated and subsequently chlorinated for 24 hours according to section 2.4.3. For

147 repeated treatments, samples were ozonated again and subsequently chlorinated during the second and the 148 third cycles.

\subsubsection{Combined $U V$ and ozone treatment experiment}

150 Samples were UV-irradiated and subsequently ozonated followed by chlorination, according to section 2.4.3, as the third step of the combined treatment. During repeated treatments, the individual treatments were repeated in the same sequence mentioned for each cycle.

\subsection{Toxicity estimation}

154 Toxicity was estimated as reported by Hansen et al. (2012a). Based on the measured concentration of the different DBPs, cytotoxicity and genotoxicity were estimated as the sum of the concentration of each compound divided by its $\mathrm{EC}_{50}$ (Equation (1)):

$$
\text { Toxicity }=\sum_{1}^{i} \frac{\mathrm{C}_{i}}{\mathrm{EC}_{50, i}}
$$

$158 \mathrm{All} \mathrm{EC}_{50}$ values were used as reported in the literature (Muellner et al., 2007; Plewa et al., 2008).

\section{3. Results and discussion}

UV, ozone and combined (UV/ozone) treatments followed by chlorination experiments were performed in cycles to investigate the effect of continued treatment in the swimming pool. Eleven DBPs usually found in

162 swimming pool water (Chowdhury et al., 2014) were examined. However, bromoform, dibromoacetonitrile

163 and trichloroacetonitrile were not detected, and hence they are not reported in the results. The $\mathrm{pH}$ was measured immediately upon arrival at the laboratory, and it was $7.2 \pm 0.1$. Furthermore, DOC in the collected water samples was $1.85 \pm 0.06 \mathrm{mg} / \mathrm{L}$. 


\subsection{Effect of treatments on chlorine consumption}

Chlorine consumption, calculated from residual chlorine measured after 24 hours' incubation, was determined after each treatment cycle during the repeated treatments. The effect of repeated treatments was observed with UV treatment, ozonation and combined UV treatment followed by ozonation (Figs. 1a, b, c).

\subsubsection{Effect of UV treatment on chlorine consumption}

UV-treated samples exhibited higher chlorine consumption compared with non-UV-treated samples (Fig 1a). Furthermore, chlorine consumption increased gradually with repeated UV treatments. Choi and Choi (2010) reported an increase in chlorine demand due to an increased fraction of low molecular organic matter following the UV treatment of drinking water. A similar trend in relation to an increase in chlorine consumption following the UV treatment of swimming pool water has also been reported in the recent literature (Cheema et al., 2017; Cimetiere and De Laat, 2014; Spiliotopoulou et al., 2015).

\subsubsection{Effect of ozone treatment on chlorine consumption}

An increase in chlorine consumption was observed following the ozonation of pool water compared with non-ozonated pool samples (Fig 1b); however, it remained constant with repeated ozonation. A similar chlorine reactivity trend for the ozonation of pool water has also been reported in the recent literature (Cheema et al., 2017; Hansen et al., 2016). Hansen et al. (2016) suggested that an increase in chlorine consumption following ozonation is likely due to the radical oxidation of precursors. This is supported by the findings of De Vera et al. (2015) where increased chlorine consumption was observed during ozonation of drinking water added hydrogen peroxide (enhancing the ${ }^{\circ} \mathrm{OH}$ radical oxidation) while a decrease was observed in samples added tertiary butanol (quenching the ${ }^{\circ} \mathrm{OH}$ radical oxidation); both compared with the chlorine consumption of a non-ozonated sample.

\subsubsection{Effect of combined treatment on chlorine consumption}

Chlorine consumption increased after the first combined treatment compared to non-treated samples (Fig. 1c), indicating that the initial ozone treatment was not enough to saturate the chlorine reactivity of DOC created by the UV treatment as the chlorine consumption of the combined treatment was at the same level as 
191 UV treatment. However, chlorine consumption decreased gradually with repeated combined treatments,

192 which means repeated ozonation saturated the DOC reactivity for chlorine created by UV. Cheema et al.

193 (2017) suggested that the decrease in chlorine consumption with repeated combined treatments is likely

194 because ozone continually removes the reactivity of matter created by UV irradiation of chlorine and that

195 DOC concentration and thus the amount of potential precursor decreased with repeated treatment.

\section{3.2. Effect of repeated UV treatment}

197 A low UV dose (UV lpass $_{\text {; }}$ Spiliotopoulou et al. (2015), Cheema et al. (2017)) was used, which is comparable

198 to the realistic dose applicable to swimming pool water. Furthermore, UV treatments followed by

199 chlorination were repeated in cycles, in order to investigate the effect of the continued treatment that would 200 actually occur in a swimming pool.

\section{3.2.1. Effect of UV treatment on trihalomethanes}

202 THM refers only to chlorinated and brominated by-products in this study, i.e. chloroform, 203 bromodichloromethane, dibromochloromethane and bromoform. However, dibromochloromethane was 204 under the limit of quantification, while bromoform was not detected due to low bromide concentrations in 205 the investigated pool and hence not reported. Furthermore, chloroform was the most predominant THM, 206 while bromodichloromethane was the least.

207 Chloroform concentration increased continuously with UV followed by chlorination (Fig 2a), while the 208 concentration of bromodichloromethane decreased during UV irradiation but increased during post-UV 209 chlorination (Fig 2b). The concentration of bromine-containing DBPs was expected to decrease following 210 the UV treatments as UV irradiations can easily photolyse brominated THMs (Hansen et al., 2013b). Both 211 Spiliotopoulou et al. (2015) and Cimetiere and De Laat (2014) have reported similar increases in THM 212 formation potential with UV doses in single-batch UV treatments of swimming pool water. Also in UV 213 treatment of drinking water, increased chlorine consumption and THM formation have been observed (Choi 214 and Choi, 2010; Dotson et al., 2010). An increase in by-product concentration, due to an increase in chlorine 215 consumption following UV treatment, is likely because of the increased reactivity of any remaining DOC 216 (Cheema et al., 2017). 
217 Overall, total THM concentration increased following repeated UV treatments (Fig 2j) and a slight increase 218 in the bromine incorporation was found. Other studies have also reported increased bromine incorporation 219 during post-UV chlorination (Dotson et al., 2010; Spiliotopoulou et al., 2015) and Spiliotopoulou et al. 220 (2015) suggests that UV continually photodegrades the bromine-carbon bond, which means that more 221 bromide might be liberated into the water and oxidized by post-UV chlorination to form hypobromous acid 222 which then reacts with DOC and forms new brominated DBPs.

\subsubsection{Effect of $U V$ treatment on haloacetonitriles}

HAN refers to dichloroacetonitrile and bromochloroacetonitrile in this study. Dichloroacetonitrile was the most predominant, while bromochloroacetonitrile was the least. Bromochloroacetonitrile concentration decreased following UV irradiation, likely due to its photodegradation, as bromine-containing DBPs are photosensitive to UV irradiation. However, the concentration of bromochloroacetonitrile increased significantly during post-UV chlorination (Fig 2d). On the other hand, dichloroacetonitrile concentration increased following UV treatment, likely due to its photo-induction (Fig 2e). Spiliotopoulou et al. (2015) reported on the photo-induction of dichloroacetonitrile with UV irradiation, and Weng et al. (2012) also reported an increase in dichloroacetonitrile formation due to UV irradiation and chlorination. There was no definite trend observed for bromochloroacetonitrile. Overall, total HAN concentration increased in line with repeated UV treatments (Fig 2i). Cheema et al. (2017) and Cimetiere and De Laat (2014) reported similar increases in HAN concentrations with single-batch UV treatments of swimming pool water.

\subsubsection{Effect of UV treatment on miscellaneous DBPs}

Trichloronitromethane concentration increased gradually with repeated UV treatments and chlorination (Fig 2f). Moreover, trichloronitromethane concentration decreased with UV irradiation, likely due to photodegradation as trichloronitromethane is photodegradable (Deng et al., 2014; Fang et al., 2013). Dichloropropanone concentration also increased in line with repeated UV treatments (Fig 2g), likely due to its photo-induction, while it increased slightly further during post-UV chlorination. Spiliotopoulou et al. (2015) reported a similar increase in dichloropropanone concentration following the UV treatment of 
swimming pool water. The concentration pattern for trichloropropanone was similar to trichloronitromethane 243 (Fig 2h).

\subsubsection{Effect of UV treatment on predicted toxicity}

245 To evaluate the effect of DBP formation on bathers' health, cytotoxicity and genotoxicity were estimated 246 using Equation (1), as described in the material and method section. Cytotoxicity was present mainly as a result of HAN, while genotoxicity was contributed mainly by trichloronitromethane. Cytotoxicity increased gradually in line with repeated UV treatment, as expected, similar to HAN concentration (Fig 2k). Genotoxicity increased gradually during repeated UV treatments while having a significant increase during post-UV chlorination but a repeated decrease during UV irradiation (Fig 21).

In summary, the concentrations of all DBPs increased following repeated UV treatments. Furthermore, concentrations of DBPs did not increase during UV irradiation but did increase during post-UV chlorination treatments except for dichloroacetonitrile and dichloropropanone, the concentrations of which increased during both UV irradiation and post-UV treatment.

\subsection{Effect of repeated ozone treatment}

The low ozone dosage ( $2 \mathrm{ppm})$ investigated in this study is comparable to the realistic ozone dosage applicable to swimming pool water (Rice, 1995). Furthermore, ozone treatment followed by chlorination was repeated in cycles to investigate the effect of continued treatment. In general, the level of most DBPs was not affected by ozone treatment followed by chlorination in swimming pool water.

\subsubsection{Effect of ozone treatment on trihalomethanes}

Chloroform was most abundant of the THMs together with a small amount of bromodichloromethane, while dibromochlormethane concentration was detected below the limit of quantification (Fig 3c) and bromoform was not detected at all and hence is not reported. Chloroform concentration increased with ozone treatment followed by chlorination, likely due to the radical oxidation of DOC present in pool water, though it remained unchanged in line with repeated treatments (Fig 3a). A similar increased trend in chloroform concentration was also observed in the recent literature during single-batch ozone treatments followed by the 
chlorination of swimming pool water (Cheema et al., 2017). In general, ozone is found to reduce the THM formation during post-ozone chlorination in drinking water (De Vera et al., 2015; Hua and Reckhow, 2013; Mao et al., 2014); however in some cases an increase have been observed at low ozone doses $(<3 \mathrm{mg} / \mathrm{L})$ (Mao et al., 2014). The difference in pool water and drinking water are the type of precursor present. In the swimming pool, the water are recirculated and continuous chlorinated which make the DOC less reactive towards ozone and a half lifetime of $2 \mathrm{mg} / \mathrm{L}$ ozone at approximately $20 \mathrm{~min}$ have been reported (Hansen et al., 2016). Whereas, drinking water typically produced from surface or ground water tends to react fast with ozone and direct oxidation is the main reaction (De Vera et al., 2015; Hansen et al., 2016). However, drinking water treated with $\mathrm{O}_{3} / \mathrm{H}_{2} \mathrm{O}_{2}$ which enhance the ${ }^{\circ} \mathrm{OH}$ radical production, have increased THM formation (De Vera et al., 2015). Thus in ozonation of swimming pool water, the oxidation of the DOC mainly occurs as radical oxidation rather than direct oxidation by ozone and increased THM formation can be observed. Bromodichloromethane concentration remained unaffected after ozone treatment, followed by chlorination and repeated treatments (Fig 3b). Overall, the concentration of total THM increased along with a slight increase in the bromine fraction with ozonation but remained constant following further repeated ozonation (Fig 3j).

\subsubsection{Effect of ozone treatment on haloacetonitriles}

283 Dichloroacetonitrile was most abundant of the HAN along with the least amount of bromochloroacetonitrile. 284 Furthermore, bromochloroacetonitrile concentration was detected under the limit of quantification except for its initial concentration in untreated pool water, which was detected just close to its quantification limit and hence no results are discussed further. Dichloroacetonitrile concentration increased in line with repeated ozone treatments followed by chlorination, and it is likely that the ozone treatment formed precursors and subsequent chlorination increased the formation during each cycle (Fig 3e). A similar increase in dichloroacetonitrile concentration was also reported by Hansen at al. (2016) through repeated ozone treatments followed by chlorination in swimming pool water. However after ozonation of drinking water, a decrease in formation of HAN is typically observed during the subsequent chlorination (De Vera et al., 2015; 
293 formation could be differences between the DBP-precursors in the two types of water. The swimming pool 294 water contains higher amount of anthropogenic DBP-precursors which have higher nitrogen to carbon molar ratio compared to NOM. Total HAN (tHAN) concentration also increased during repeated ozone treatments followed by chlorination, in a pattern similar to that observed for dichloroacetonitrile (Fig 3i).

\subsubsection{Effect of ozone treatment on miscellaneous DBPs}

Trichloronitromethane concentration remained unchanged during ozone treatment compared with nonozonated samples, but it increased with subsequent chlorination. During the repeated ozonation and chlorination, the trichloronitromethane concentration continuous to increase during each post-ozone chlorination, which is most likely because ozone treatment produced precursors and subsequent chlorination increased concentration thereafter. The formation of trichloronitromethane due to ozone followed by chlorination is known in drinking water (Hoigne and Bader, 1988; Mao et al., 2014; Merlet et al., 1985). Hansen et al. (2016) reported an increase in this regard during high ozone dosage exposure followed by chlorination in pool water samples mixed with fresh body fluid analogues.

Dichloropropanone was detected at low levels following ozone treatment to the level seen in non-ozonated samples (Fig 3g). However, the concentration of dichloropropanone increased considerably in line with repeated ozone treatments followed by chlorination, while trichloropropanone concentration remained unchanged for ozone treatments followed by chlorination (Fig 3h).

\subsubsection{Effect of ozone treatment on predicted toxicity}

311 Toxicity refers to cytotoxicity and genotoxicity, the former of which was contributed mainly by HAN, 312 whereas genotoxicity was mainly contributed by trichloronitromethane. Both cytotoxicity and genotoxicity 313 increased gradually in line with repeated ozone treatments followed by chlorination (Fig 3k-1), which is in 314 accordance with a previous study in which a significant increase in toxicity was observed during single-batch 315 experimental ozone treatments followed by chlorination (Cheema et al., 2017). The effect of repeated ozone treatments followed by chlorination on the formation of DBPs was different to that observed during repeating UV treatments followed by chlorination. The concentration of volatile DBPs, i.e. 
318 dichloroacetonitrile, trichloronitromethane and dichloropropanone, increased significantly in line with 319 repeated ozone treatments followed by chlorination.

\subsection{Effect of repeated combined treatment}

The combined treatment $\left(\mathrm{UV} / \mathrm{O}_{3}\right)$ reported in this study refers to the UV treatment of pool water followed by ozonation. Combined treatment followed by chlorination was performed to investigate system performance through multiple treatments using realistically low doses of both UV and ozone under controlled conditions, shifting between UV, ozone and chlorine. Experiments were performed in cycles to investigate the effect of continued treatment that would occur in an actual swimming pool. It was expected from chlorine consumption patterns (Fig 1c) that DBP formation might increase with the initial combined treatment followed by chlorination but most probably would decrease during repeated treatments in cycles.

\subsubsection{Effect of combined treatment on trihalomethanes}

Again chloroform was most abundant of the THMs together with a small amount of bromodichloromethane. Furthermore, chloroform concentration increased after initial combined treatment followed by chlorination (Fig 4a), likely because ozonation was unable to remove the precursors created by UV treatment, and hence chlorination produced more chloroform. Chloroform concentration decreased gradually in line with repeated combined treatment followed by chlorination, probably due to the ozonation of UV-treated water removing chloroform precursors during each cycle and thus leaving fewer precursors for the chlorination to enhance formation. The bromodichloromethane trend was similar to chloroform, in that concentration increased with the initial combined treatment followed by chlorination but gradually decreased with repeated treatments

(Fig 4b). Total THM concentration decreased with repeated combined treatment followed by chlorination, along with a decrease in the bromine-containing fraction of THM (Fig 4j).

\subsubsection{Effect of combined treatment on haloacetonitriles}

Dichloroacetonitrile was the primary detected HAN along with a small amount of bromochloroacetonitrile. However, bromochloroacetonitrile was detected close to the limit of quantification (Fig 4d), and hence its results are not discussed further herein. The concentration of dichloroacetonitrile increased considerably in 
343 line with the initial combined treatment followed by chlorination, most likely because the UV treatment

344 produced precursors which were not removed further through ozone treatment, hence enhanced chlorination 345 formation (Fig 4e). Dichloroacetonitrile concentration decreased in line with the repeated combined 346 treatment followed by chlorination, which is likely because repeated ozone treatments gradually saturated 347 reactivity created by UV. Total HAN concentration also increased with the initial combined treatment 348 followed by chlorination, and it decreased with the repeated combined treatment followed by chlorination 349 (Fig 4i).

\subsubsection{Effect of combined treatment on miscellaneous DBPs}

351 As seen from repeated UV treatment (Fig 2f) and repeated ozone treatment (Fig 3f), both treatment methods 352 created precursors which during chlorination formed trichloronitromethane and increasing concentrations 353 were observed in both cases. With the combined treatment, an increased trichloronitromethane concentration 354 was observed after the first combined treatment and chlorination, but the concentration decreased after the following combined treatments with a smaller increase during post-treatment chlorination. As trichloronitromethane is photodegradable (Deng et al., 2014; Fang et al., 2013), the decrease is due to photolysis in the UV treatment. The decrease in the formation of trichloronitromethane during post-treatment chlorination could be due to depletion of precursor. Thus there is a synergetic effect, where ozonation and (2017) reported a decrease in dichloropropanone concentration after ozone treatment followed by chlorination. During combined treatment, it is likely because UV treatment created precursors and ozone treatment could not remove those precursors, and so more dichloropropanone was produced during the combined treatment followed by chlorination. Trichloropropanone concentration increased with the initial combined treatment followed by chlorination, while the concentration remained unchanged further with 
repeated combined treatments (Fig 4h). Cheema et al. (2017) reported a decrease in trichloropropanone concentration with UV irradiation, while concentration increased during post-UV chlorination.

\subsubsection{Effect of combined treatment on predicted toxicity}

Toxicity was estimated in terms of cytotoxicity and genotoxicity. Cytotoxicity was mainly contributed by HAN, while genotoxicity was mainly contributed by trichloronitriomethane. Both cytotoxicity and genotoxicity increased during the first treatment but decreased gradually with repeated treatments (Fig 4k-1).

Overall, toxicity decreased with repeated combined treatments.

\subsection{Proposed system}

Based on the experimental results, a treatment system is proposed with a UV system placed in a side stream to the recirculation flow, followed by an ozone dosing point and a small reaction chamber with a volume that allows a 1-2 min reaction time before returning to the main recirculation flow.

Therefore, water from a swimming pool or other continuously chlorinated water system will be treated in a recirculation stream first with UV light and then dosed with ozone before chlorine is added or the treatment stream returns to be mixed with the chlorinated water. This side stream UV/ozone treatment is predicted to improve swimming pool water quality.

As an example, a system, in this case the hot water pool in Gladsaxe municipal pool, is $50 \mathrm{~m}^{3}$ in size and the return flow is $100 \mathrm{~m}^{3} / \mathrm{h}$, while the flow through the side stream UV is $20 \mathrm{~m}^{3} / \mathrm{h}$. If an ozone injector and a 600 $\mathrm{L}$ reaction tank were added after the UV system, we predict that a dose of $50 \mathrm{~g} / \mathrm{h}$ of ozone could be added to the water continuously, which would then react with the reactive organic matter in the water and be consumed completely during the 2 min retention time in the reaction tank (Fig 5). If the same ozone dose were added to the return stream without prior UV activation, it is predicted from the results in Hansen et al. (2016) that the required reaction tank that allows the complete reaction of ozone would hold the water for 30 minutes, which would be a tank of $10 \mathrm{~m}^{3}$. Additionally, Hansen et al. (2016) predict that this ozone treatment would increase the formation of chlorination by-products when pool water is not being polluted, while the 
392 abovementioned results predict that when UV is applied before ozonation, by-product formation always 393 decreases with ozone treatment.

\section{4. Conclusions}

395 UV irradiation effectively photolysed bromine-containing DBPs, trichloronitromethane and 396 trichloropropanone; however, the concentration of all DBPs and predicted toxicity increased during repeated 397 post-UV chlorination. Furthermore, ozonation was effective in oxidising dichloroacetonitrile and 398 trichloronitromethane, whereas DBP concentrations increased during post-ozone chlorination. However, 399 concentrations of most DBPs decreased with repeated combined treatments followed by chlorination. 400 Dichloropropanone and trichloropropanone concentrations increased with the first combined treatment 401 followed by chlorination but remained unchanged with repeated combined treatments, which are further 402 expected to decrease with continuous treatments. Predicted toxicity significantly decreased compared to the 403 control during repeated combined treatments.

\section{5. Acknowledgement}

405 The authors would like to thank Scan Research A/S for making available the laboratory's UV system for the 406 study. Furthermore, we wish to thank Gladsaxe public swimming pool's staff for their cooperation. Waqas 407 Cheema is also grateful to NUST and DTU for their support of this work. 


\section{References}

Bader, H., Hoigné, J., 1981. Determination of ozone in water by the indigo method. Water Res. 15, 449-456.

Cheema, W.A., Kaarsholm, K.M.S., Andersen, H.R., 2017. Combined UV treatment and ozonation for the removal of by-product precursors in swimming pool water. Water Res. 110, 141-149.

Choi, Y., Choi, Y.-J., 2010. The effects of UV disinfection on drinking water quality in distribution systems. Water Res. 44, 115-122.

Chowdhury, S., Alhooshani, K., Karanfil, T., 2014. Disinfection byproducts in swimming pool: Occurrences, implications and future needs. Water Res. 53, 68-109.

Cimetiere, N., De Laat, J., 2014. Effects of UV-dechloramination of swimming pool water on the formation of disinfection by-products: A lab-scale study. Microchem. J. 112, 34-41.

De Vera, G.A., Stalter, D., Gernjak, W., Weinberg, H.S., Keller, J., Farré, M.J., 2015. Towards reducing DBP formation potential of drinking water by favouring direct ozone over hydroxyl radical reactions during ozonation. Water Res. 87, 49-58.

Deng, L., Wu, Z., Yang, C., Wang, Y.L., 2014. Photodegradation of Trace Trichloronitromethane in Water under UV Irradiation. J. Chem. 2014, 1-8.

Dotson, A.D., Keen, V.S., Metz, D., Linden, K.G., 2010. UV/H2O2 treatment of drinking water increases post-chlorination DBP formation. Water Res. 44, 3703-3713.

Eichelsdörfer, D., Jandik, J., 1985. Long Contact Time Ozanation For Swimming Pool Water Treatment. Ozone Sci. Eng. 7, 93-106.

Fang, J.Y., Ling, L., Shang, C., 2013. Kinetics and mechanisms of pH-dependent degradation of halonitromethanes by UV photolysis. Water Res. 47, 1257-1266.

Hansen, K.M.S., Albrechtsen, H.-J., Andersen, H.R., 2013a. Optimal pH in chlorinated swimming pools balancing formation of by-products. J. Water Health 11, 465-472.

Hansen, K.M.S., Spiliotopoulou, A., Cheema, W.A., Andersen, H.R., 2016. Effect of ozonation of swimming pool water on formation of volatile disinfection by-products - A laboratory study. Chem. Eng. J. 289, $277-285$.

Hansen, K.M.S., Willach, S., Antoniou, M.G., Mosbæk, H., Albrechtsen, H.J., Andersen, H.R., 2012a. Effect of $\mathrm{pH}$ on the formation of disinfection byproducts in swimming pool water - Is less THM better? Water Res. 46, 6399-6409.

Hansen, K.M.S., Willach, S., Mosbæk, H., Andersen, H.R., 2012b. Particles in swimming pool filters - does pH determine the DBP formation? Chemosphere 87, 241-247.

Hansen, K.M.S., Zortea, R., Piketty, A., Vega, S.R., Andersen, H.R., 2013b. Photolytic removal of DBPs by medium pressure UV in swimming pool water. Sci. Total Environ. 443, 850-856.

Hoigne, J., Bader, H., 1988. The formation of trichloronitromethane (chloropicrin) and chloroform in a combined ozonation/chlorination treatment of drinking water. Water Res. 22, 313-319.

Hua, G., Kim, J., Reckhow, D.A., 2014. Disinfection byproduct formation from lignin precursors. Water Res. 63, 285-295.

Hua, G., Reckhow, D.A., 2013. Effect of pre-ozonation on the formation and speciation of DBPs. Water Res. 47, 4322-4330.

Kanan, A., 2010. Occurrence and formation of disinfection by-products in indoor swimming pools water. 
Clemson University.

Kristensen, G.H., Klausen, M.M., Andersen, H.R., 2010. Testing of different treatment technologies in swimming pools (In Danish: Afprøvning af forskellige renseteknologier på svommebade). Danish Nature Agency, Denmark. http://www.naturstyrelsen.dk/.

Kristensen, G.H., Klausen, M.M., Andersen, H.R., Erdinger, L., Lauritsen, F.R., Arvin, E., Albrechtsen, H.J., 2009. Full scale test of UV-based water treatment technologies at Gladsaxe Sportcentre - with and without advanced oxidation mechanisms, in: The Third International Swimming Pool and Spa Conference, London, March.

Kristiana, I., Lethorn, A., Joll, C., Heitz, A., 2014. To add or not to add: The use of quenching agents for the analysis of disinfection by-products in water samples. Water Res. 59, 90-98.

Mao, Y., Wang, X., Yang, H., Wang, H., Xie, Y.F., 2014. Effects of ozonation on disinfection byproduct formation and speciation during subsequent chlorination. Chemosphere 117, 515-520.

Merlet, N., Thibaud, H., Dore, M., 1985. Chloropicrin formation during oxidative treatments in the preparation of drinking water. Sci. Total Environ. 47, 223-228.

Muellner, M.G., Wagner, E.D., Mccalla, K., Richardson, S.D., Woo, Y.T., Plewa, M.J., 2007. Haloacetonitriles vs. regulated haloacetic acids: Are nitrogen-containing DBFs more toxic? Environ. Sci. Technol. 41, 645-651.

Pinkernell, U., Nowack, B., Gallard, H., von Gunten, U., 2000. Methods for the photometric determination of reactive bromine and chlorine species with ABTS. Water Res. 34, 4343-4350.

Plewa, M.J., Wagner, E.D., Muellner, M.G., Hsu, K.M., Richardson, S.D., 2008. Comparative mammalian cell toxicity of N-DBPs and C-DBPs, in: Karanfil, T., SW, K., Xie, Y. (Eds.), Disinfection By-Products in Drinking Water: Occurrence, Formation, Helth Effects, and Control, Acs Symposium Series. American Chemical Society, Washington, DC, pp. 36-50.

PWTAG, 2009. Swimming pool water: treatment and quality standards for pools and spas, Second. ed. Countrywide Publications, Suffolk, UK.

Rice, R.G., 1995. Chemistries of ozone for municipal pool and spa water treatment. J. Swim. pool spa Ind. 1, 25-44.

Richardson, S.D., Plewa, M.J., Wagner, E.D., Schoeny, R., DeMarini, D.M., 2007. Occurrence, genotoxicity, and carcinogenicity of regulated and emerging disinfection by-products in drinking water: A review and roadmap for research. Mutat. Res. - Rev. Mutat. Res. 636, 178-242.

Schmalz, C., Frimmel, F.H., Zwiener, C., 2011. Trichloramine in swimming pools - Formation and mass transfer. Water Res. 45, 2681-2690.

Soltermann, F., Widler, T., Canonica, S., von Gunten, U., 2014. Photolysis of inorganic chloramines and efficiency of trichloramine abatement by UV treatment of swimming pool water. Water Res. 56, 280291.

Spiliotopoulou, A., Hansen, K.M.S., Andersen, H.R., 2015. Secondary formation of disinfection by-products by UV treatment of swimming pool water. Sci. Total Environ. 520, 96-105.

Weng, S.C., Li, J., Blatchley, E.R., 2012. Effects of UV254 irradiation on residual chlorine and DBPs in chlorination of model organic-N precursors in swimming pools. Water Res. 46, 2674-2682.

WHO, 2006. Guidelines for safe recreational water environments. Volume 2, Swimming pools and similar environments. World Health Organization, WHO Press, Geneva, Switzerland. 
Figure 1. Chlorine consumption at $25^{\circ} \mathrm{C}$ in $24 \mathrm{~h}$ with a) UV treatment, b) ozone treatment and c) combined UV and ozone treatment.

Figure 2. Concentrations of investigated DBPs with repeated UV treatment (a-h), (i), and (j) represents total HAN and total THM, and (k) and (I) represent cytotoxicity and genotoxicity, respectively. The lower dotted part of (j) and the \% indicate the amount of bromine incorporated in the total trihalomethane. The error bars represent the standard deviation of three replicates. The dotted line indicates the limit of quantification (LOQ). $\mathrm{DC}, \mathrm{Cl}_{2}$ are denotation for chlorinated untreated samples.

Figure 3. Concentration of investigated DBPs with repeated ozone treatment (a-h). (i) and (j) represent total HAN and total THM, and (k) and (I) represent cytotoxicity and genotoxicity, respectively. The lower dotted part of $(j)$ and the \% indicate the amount of bromine incorporated in the total trihalomethane. The error bars represent the standard deviation of three replicates. The dotted line indicates the limit of quantification (LOQ). $\mathrm{DC}, \mathrm{Cl}_{2}$ are denotation for chlorinated untreated samples.

Figure 4. Concentrations of investigated DBPs with repeated combined UV and ozone treatments (a-h). (i) and (j) represent total HAN and total THM, and (k) and (I) represent cytotoxicity and genotoxicity, respectively. The lower dotted part of $(\mathrm{j})$ and the $\%$ indicate the amount of bromine incorporated in the total trihalomethane. The error bars represent the standard deviation of three replicates. The dotted line indicates the limit of quantification (LOQ). $\mathrm{DC}, \mathrm{Cl}_{2}$ are denotation for chlorinated untreated samples.

Figure 5. Schematic of the proposed system 


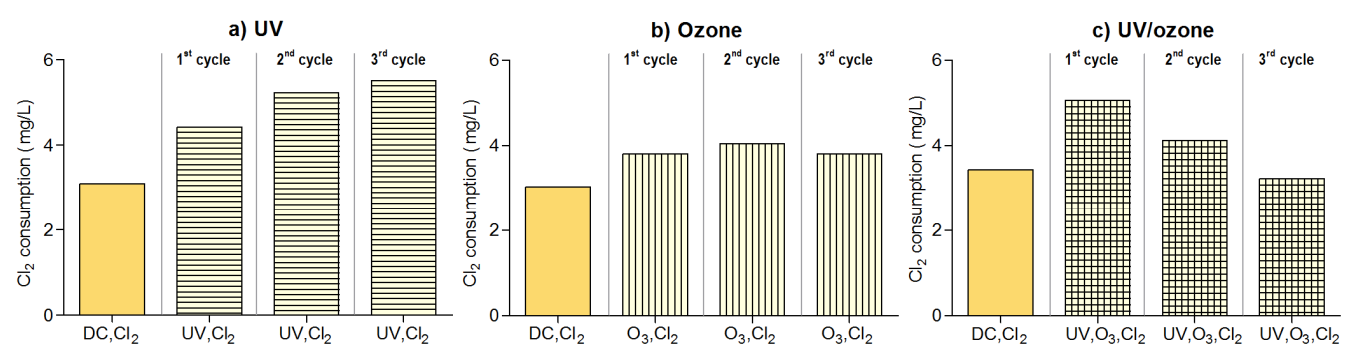



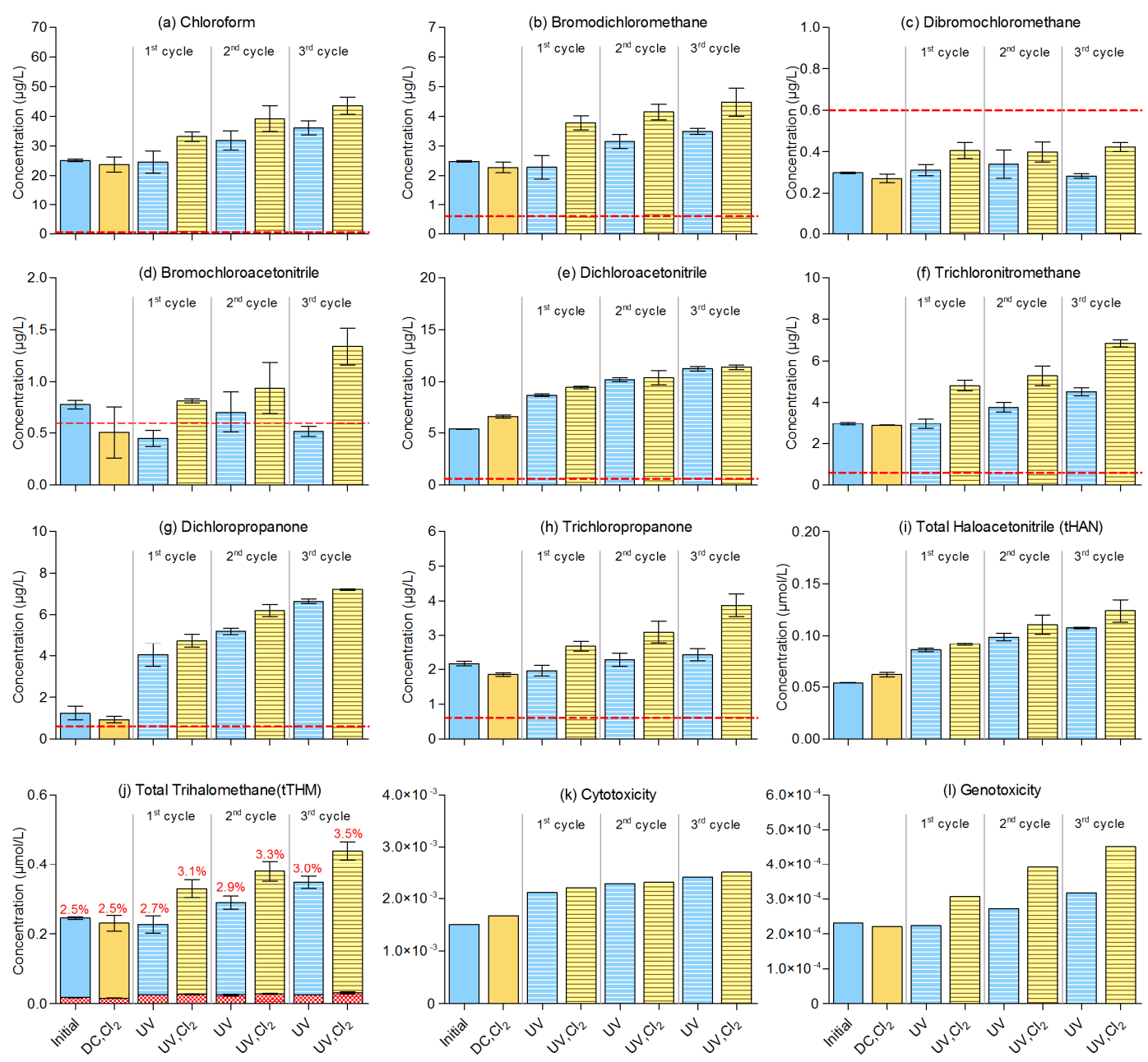

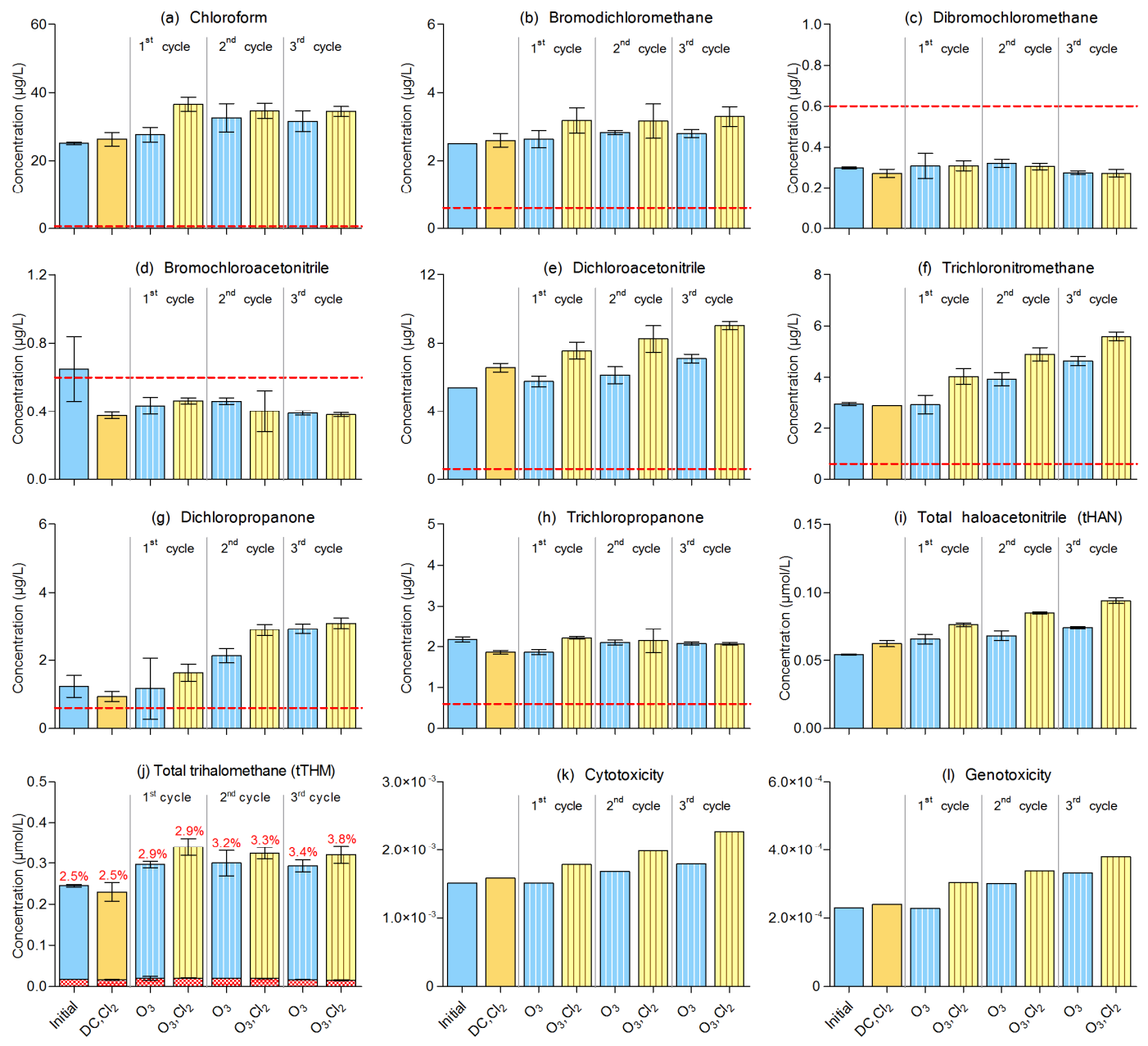

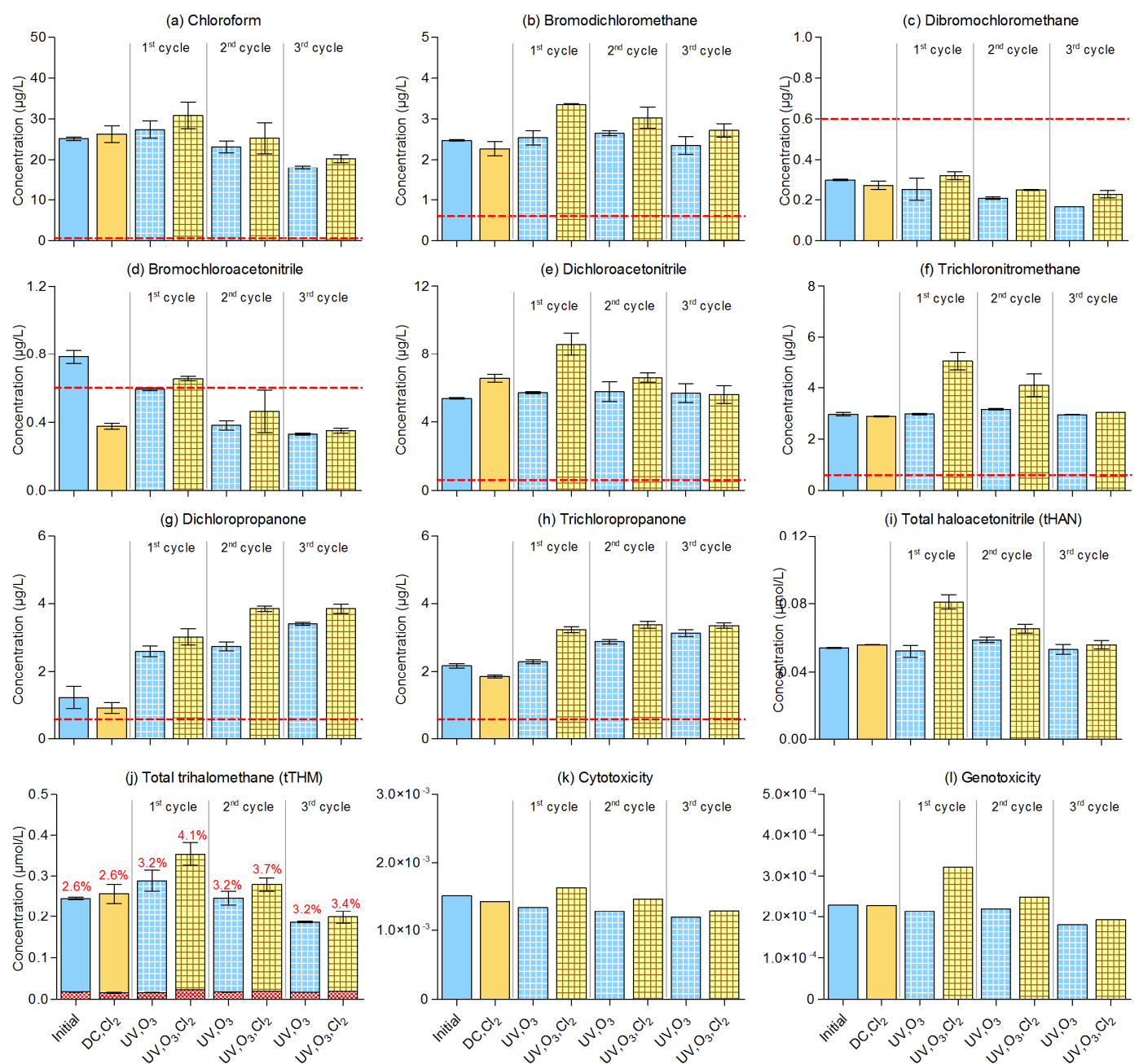


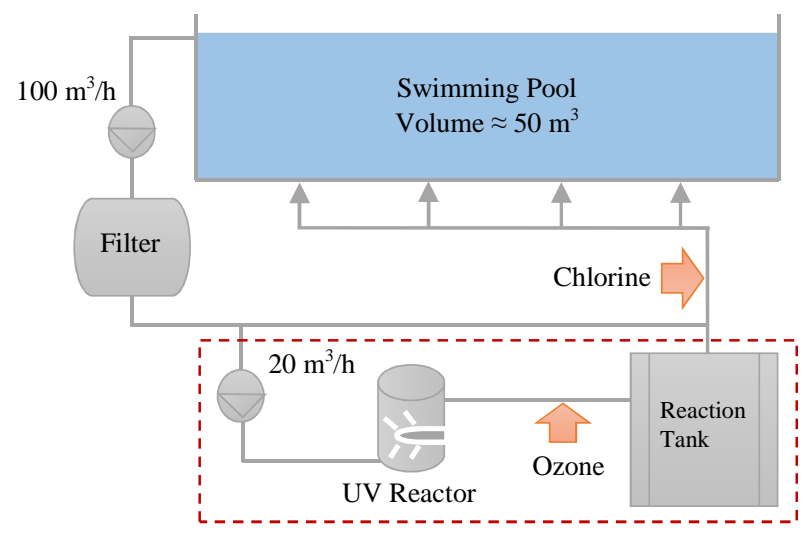




\section{Highlights}

- Repeated UV treatment with chlorination increases formation of chloro-organic DBPs

- Ozone oxidises chlorine-reactive DBP precursors but forms other uncommon DBPs

- Continuous combined UV treatment followed by ozonation decreases DBP formation

- Synergy, as ozone removes UV-formed reactivity, and UV photolyses ozone-induced DBP

- Pool water quality is predicted to improve with continuous combined treatments 